\title{
Ether-linked diamine carboxylate ionic liquid aqueous solution for efficient absorption of $\mathrm{SO}_{2}$
}

Bin Jiang ${ }^{\dagger}$, Shuai Hou ${ }^{\dagger}$ Luhong Zhang ${ }^{\dagger}, \mathrm{Na}$ Yang ${ }^{\dagger}$, Na Zhang ${ }^{\dagger}$ Xiaoming Xiao ${ }^{\dagger}$, Xiaodong Yang ${ }^{\dagger}$ Yongli Sun ${ }^{\dagger}$, Xiaowei Tantai ${ }^{* \dagger}$

${ }^{\dagger}$ School of Chemical Engineering and Technology, Tianjin University, Tianjin 300072, P. R.

China

${ }^{*}$ Corresponding author: Xiaowei Tantai. E-mail addresses: tantaixw@tju.edu.cn (Xiaowei Tantai), Tel/Fax: +86 22 27400199, School of Chemical Engineering and Technology, Tianjin University, Tianjin 300072, P. R. China. 
${ }^{1}$ H NMR data of EDPILs:

[BDMAEE][L] ${ }^{1} \mathrm{H}$ NMR (500 MHz, DMSO, 298.2K, TMS), $\delta （ \mathrm{ppm} ）$ :

1.31(3H, m), 2.61(12H, t), 3.63(4H, t), 3.91(4H, t), 4.21(1H, s), 4.82(1H, s), $7.81(1 \mathrm{H}, \mathrm{s})$

[BDMAEE][L]2 ${ }^{1} \mathrm{H}$ NMR (500 MHz, DMSO, 298.2K, TMS), $\delta(\mathrm{ppm}): 1.31(6 \mathrm{H}, \mathrm{m})$, 2.61(12H, t), 3.63(4H, m), 3.91(4H, m), 4.21(2H, s), 4.82(2H, s), 7.81(2H,s)

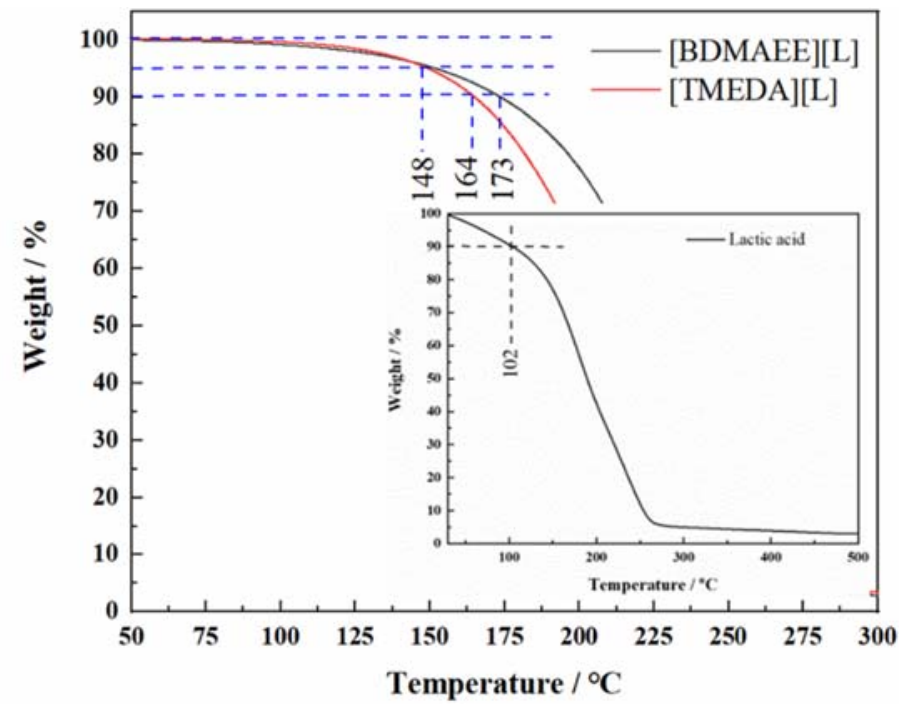

Figure S1. TGA curves of [BDMAEE][L], [TMEDA][L] and lactic acid with a 10 ${ }^{\circ} \mathrm{C} /$ min temperature heating rate to $800{ }^{\circ} \mathrm{C}$ under the $\mathrm{N}_{2}$ atmosphere.

We employed a lactic acid of $99.7 \%$ purity and $85 \%$ content. We further decreased the water content below $6 \mathrm{wt} \%$ via evaporation under vacuum before thermal gravimetric analysis was carried out. It was evident that the weight loss before $100{ }^{\circ} \mathrm{C}$ was approximately $10 \mathrm{wt} \%$, this may suggest the relatively poor thermal stability of the lactate anion.

Table S1. The water content of the prepared PILs.

\begin{tabular}{cc}
\hline PILs & Water contents $(w t \%)$ \\
\hline$[$ TMEDA $][\mathrm{L}]$ & $0.1030 \pm 0.0075$ \\
\hline
\end{tabular}




\begin{tabular}{lc}
\hline TMEDA $][\mathrm{L}]_{2}$ & $0.1244 \pm 0.0050$ \\
{$[\mathrm{BDMAEE}][\mathrm{L}]$} & $0 . .1156 \pm 0.0085$ \\
{$[\mathrm{BDMAEE}][\mathrm{L}]_{2}$} & $0.1458 \pm 0.0060$ \\
\hline
\end{tabular}

Quantum chemical calculations. The geometries of the $\mathrm{SO}_{2}, \mathrm{BDMAEE}, \mathrm{TMEDA}$, and lactic acid were constructed using GaussView 5.0. To investigate the interaction between PILs and $\mathrm{SO}_{2}, \mathrm{SO}_{2}$ molecules were added to [BDMAEE][L] or [TMEDA][L] and optimized to obtain the initial structures of $\mathrm{PILs}-\mathrm{nSO}_{2}$ complexes using Molclus software and Gaussian 09 program. Specifically, 500 initial structures of the PILs-nSO $\mathrm{S}_{2}$ complexes were randomly and irregularly engendered using the Genmer tool of the Molclus program. They were then pre-optimized at the PM6 level by using Gaussian 09 program. According to the energy sequence and previous study, several optimized configurations were selected for further density-functional theory (DFT) calculations. Widely used, B3LYP/6-311+G(d,p) computational model was used to conduct all the DFT calculations. Frequency calculations were carried out at the same theoretical level for each optimized complex structures to confirm there was no imaginary frequency. Thus, all the configurations were verified to be local minima. The interaction energy including the basis set superposition errors (BSSE) was determined using the counterpoise method. 


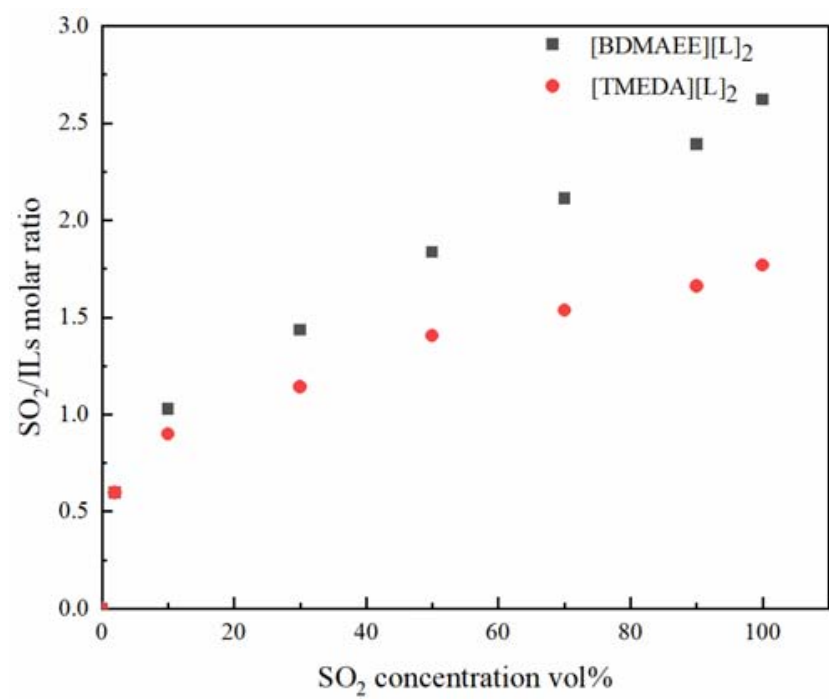

Figure S2. Absorption capacity of $\mathrm{SO}_{2}$ in $[\mathrm{BDMAEE}][\mathrm{L}]_{2}$ and $[\mathrm{TMEDA}][\mathrm{L}]_{2}$ with respect to the concentration of $\mathrm{SO}_{2}$ at $40{ }^{\circ} \mathrm{C}$.

Table S2. The reaction equilibrium constant $(\mathrm{K})$ and related $\mathrm{SO}_{2}$ absorption experiments data for the absorption enthalpy calculation. (The $\mathrm{SO}_{2}$ concentration was $100 \%$ and the pressure was 1 bar)

\begin{tabular}{|c|c|c|c|c|c|}
\hline \multicolumn{3}{|c|}{$[\mathrm{BDMAEE}][\mathrm{L}]_{2}$} & \multicolumn{3}{|c|}{$[\mathrm{TMEDA}][\mathrm{L}]_{2}$} \\
\hline $\mathrm{T}\left({ }^{\circ} \mathrm{C}\right)$ & $\begin{array}{l}\text { Capacity } \\
(\mathrm{mol} / \mathrm{mol})\end{array}$ & $\mathrm{K}$ & $\mathrm{T}\left({ }^{\circ} \mathrm{C}\right)$ & $\begin{array}{l}\text { Capacity } \\
(\mathrm{mol} / \mathrm{mol})\end{array}$ & K \\
\hline 20 & 2.921 & 37.119 & 20 & 1.925 & 25.667 \\
\hline 30 & 2.854 & 19.548 & 30 & 1.864 & 13.706 \\
\hline 40 & 2.621 & 6.916 & 40 & 1.768 & 7.621 \\
\hline 50 & 1.948 & 1.853 & 50 & 1.690 & 5.445 \\
\hline 60 & 1.640 & 1.206 & 60 & 1.492 & 2.937 \\
\hline
\end{tabular}




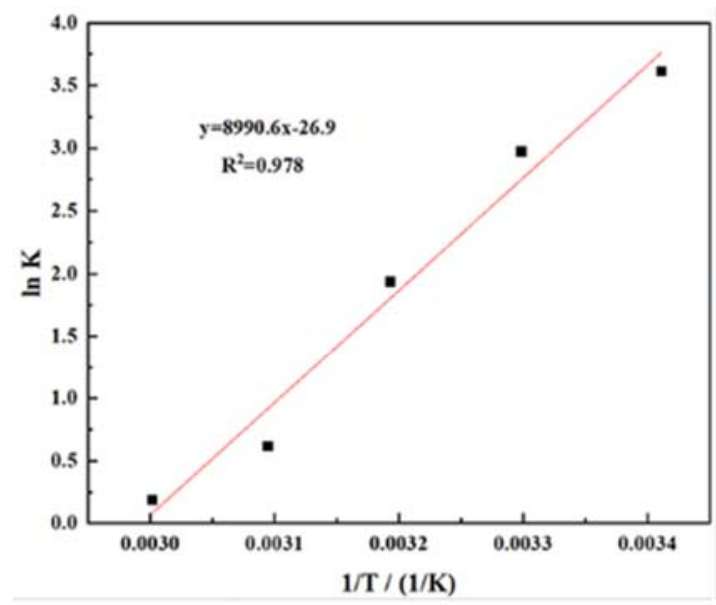

(a)

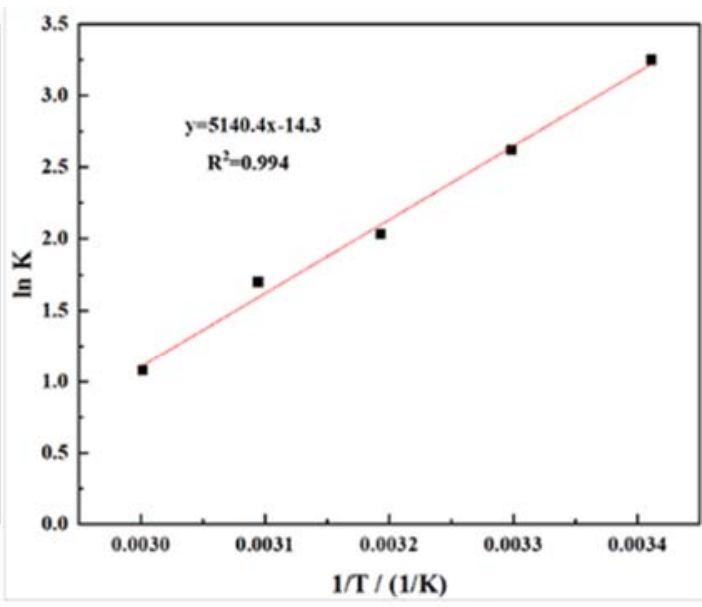

(b)

Figure S3. The linear relationship between $\operatorname{lnK}$ and $1 / \mathrm{T}$ for (a) [BDMAEE][L]2 and (b) $[$ TMEDA] $][\mathrm{L}] 2$.

Physical properties of absorbents. The densities and viscosities of EDPILs aq at $25{ }^{\circ} \mathrm{C}$ are listed in Table S2. The properties of the prepared absorbents increased with an increase in lactic acid/diamine ratios and the EDPILs concentrations. Moreover, the viscosities of all studied absorbents ranged from 1.20-6.58 cP, which were significantly lower than those of pure ILs. This indicated that the viscosities of the absorbents could be dramatically decreased via blending EDPILs with water. Conventionally, low viscosities improved the efficiency of heat and mass transfer. Thus it can be deduced that the studied absorbents with low viscosities may have a practical commercial application.

Table S3. Densities and Viscosities of the studied absorbents $\left(25^{\circ} \mathrm{C}\right)$.

\begin{tabular}{cccc}
\hline ILs aqueous solution & Concentration & Density $\left(\mathrm{g} / \mathrm{cm}^{3}\right)$ & Viscosity $(\mathrm{cP})$ \\
\hline$[$ BDMAEE] $[\mathrm{L}](1: 2)$ & $19.6 \mathrm{wt} \%$ ILs & 1.0376 & 1.20 \\
{$[$ BDMAEE] $[\mathrm{L}](1: 2)$} & $30.1 \mathrm{wt} \%$ ILs & 1.0557 & 1.28 \\
\hline
\end{tabular}




\begin{tabular}{lccc}
\hline [BDMAEE][L] $(1: 2)$ & $39.9 \mathrm{wt} \%$ ILs & 1.0738 & 1.76 \\
{$[$ BDMAEE][L] $(1: 2)$} & $49.8 \mathrm{wt} \%$ ILs & 1.1235 & 2.86 \\
{$[$ BDMAEE][L] (1:2) } & $60.3 \mathrm{wt} \%$ ILs & 1.1348 & 6.58 \\
\hline
\end{tabular}

Table S4. the $\mathrm{SO}_{2} / \mathrm{CO}_{2}$ selectivity of [BDMAEE][L]2 aqueous solution (50 wt $\left.\%\right)$

\begin{tabular}{cccccccc}
\hline & \multicolumn{2}{c}{$\mathrm{mol} \mathrm{SO}_{2} / \mathrm{mol} \mathrm{IL}$} & & $\mathrm{mol} \mathrm{CO}_{2} / \mathrm{mol} \mathrm{IL}$ & & \multicolumn{2}{c}{$\mathrm{SO}_{2} / \mathrm{CO}_{2}$ selectivity } \\
\cline { 2 - 3 } ILs aqueous solution & $2 \mathrm{vol} \%$ & $100 \mathrm{vol} \%$ & & $100 \mathrm{vol} \%$ & & $\mathrm{~S}_{0.2 / 1}$ & $\mathrm{~S}_{1 / 1}$ \\
[BDMAEE][L]2 aq & 1.040 & 2.815 & & 0.183 & & 5.7 & 15.4
\end{tabular}

$\mathrm{S}_{0.2 / 1}$ : the molar absorption capasity ratio of 0.2 vol\% $\mathrm{SO}_{2}$ and 100 vol\% $\mathrm{CO}_{2} \mathrm{~S}_{1 / 1}$ : the molar absorption capasity ratio of $100 \mathrm{vol} \% \mathrm{SO}_{2}$ and $100 \mathrm{vol} \% \mathrm{CO}_{2}$

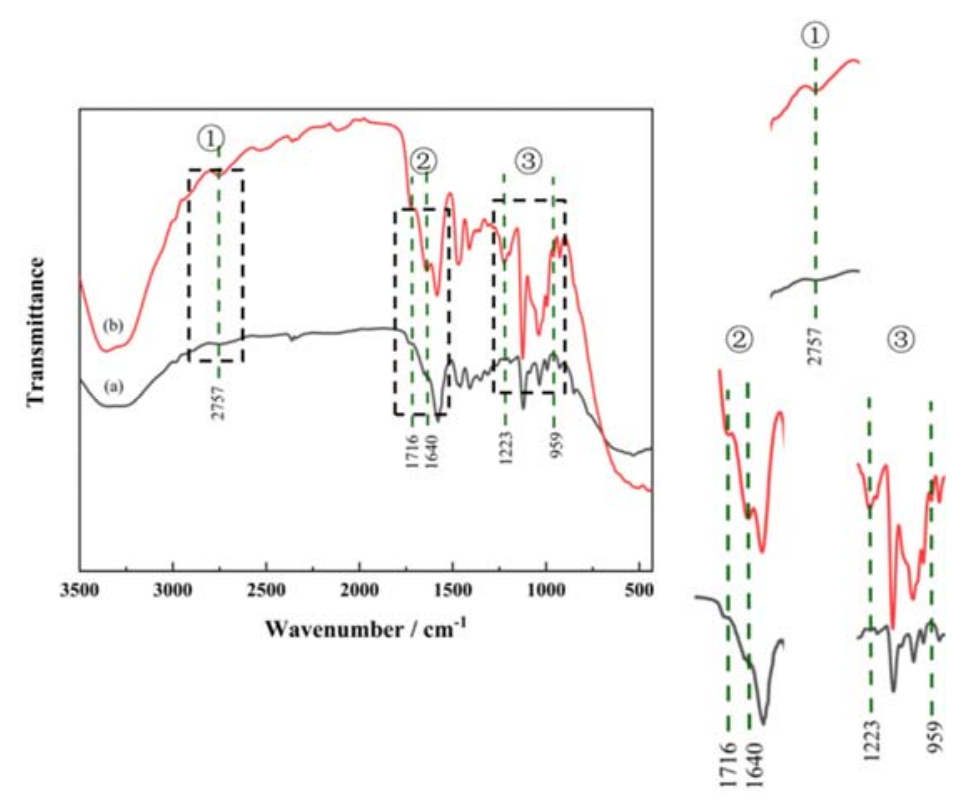

Figure S4. FTIR spectra in detail of $50 \mathrm{wt} \%[\mathrm{BDMAEE}][\mathrm{L}]_{2}$ aq before (a) and after (b) absorption of $\mathrm{SO}_{2}$. 